AperTO - Archivio Istituzionale Open Access dell'Università di Torino

\title{
Hydrothermal Alteration of Glass to Chrysotile
}

\section{This is the author's manuscript}

Original Citation:

Availability:

This version is available http://hdl.handle.net/2318/112222

since 2016-07-14T19:17:16Z

Published version:

DOI:10.1111/j.1551-2916.2012.05323.x

Terms of use:

Open Access

Anyone can freely access the full text of works made available as "Open Access". Works made available under a Creative Commons license can be used according to the terms and conditions of said license. Use of all other works requires consent of the right holder (author or publisher) if not exempted from copyright protection by the applicable law. 


\section{(3) \\ UNIVERSITÀ DEGLI STUDI DI TORINO}

This is an author version of the contribution published on:

Questa è la versione dell'autore dell'opera:

Journal of the American Ceramic Society, 95, 2012

DOI: 10.1111/j.1551-2916.2012.05323.x

The definitive version is available at:

La versione definitiva è disponibile alla URL:

http://onlinelibrary.wiley.com/doi/10.1111/i.1551-2916.2012.05323.x/pdf 


\title{
Hydrothermal Alteration of Glass to Chrysotile
}

\author{
A. Bloise, ${ }^{\ddagger, \dagger}$ E. Belluso, ${ }^{\S, q, k}$ M. Catalano, ${ }^{\ddagger \ddagger}$ E. Barrese,${ }^{\ddagger}$ D. Miriello, ${ }^{\ddagger}$ and C. Apollaro ${ }^{\ddagger}$ \\ Department of Earth Sciences, University of Calabria, Arcavacata di Rende (CS) 87036, Italy \\ Department of Earth Sciences, University of Torino, Torino 10125, Italy \\ Geosciences and Geo-resources Institute (CNR), Torino section, Torino 10125, Italy \\ kNIS Centre of Excellence, Via Quarello 11, Torino 10125, Italy \\ 扯 \\ Department of Physics, University of Calabria, Arcavacata di Rende (CS) 87036, Italy
}

Chrysotile fibers were synthesized from glass in hydrothermal conditions. The starting materials were first held at $1650^{\circ} \mathrm{C}$ and then rapidly quenched down to room temperature. The resulting glass, after the addition of mineralizing agents, was hydrothermically altered in the following conditions: temperature $300^{\circ} \mathrm{C}-400^{\circ} \mathrm{C}$; pressure $100-200 \mathrm{MPa}$; time $48-480 \mathrm{~h}$. X-ray powder diffraction, scanning and transmission electron microscopy were used to examine/study the starting materials and products. Cylindrical fiber morphology was prevalent, but proto-chrysotile was also detected, not entirely showing welldefined crystallinity, as revealed by electron diffraction patterns of selected areas. The mineralizing agent and chemical composition of the glass play an important role in the yield of chrysotile fibers. The effect of growth parameters on the size and abundance of chrysotile fibers is also discussed, in the light of possible recrystallization of glass obtained by thermal treatment of chrysotile-asbestos-containing materials.

I.

Introduction

HRYSOTILE is a phyllosilicate with ideal chemical formula

$\mathrm{C}$ $\mathrm{Mg}_{3} \mathrm{Si}_{2} \mathrm{O}_{5}(\mathrm{OH})_{4}$, belonging to the serpentine group ${ }^{1}$ and growing with asbestiform morphology (i.e., fibers with length $>5 \mathrm{~lm}$, width $<3$ $\mathrm{lm}$, and aspect ratio $>3$ ). The term asbestos indicates the asbestiform varieties of five amphiboles and chrysotile minerals. Although chrysotile fibers have good technological properties, ${ }^{2}$ if inhaled in high doses, they may cause several respiratory diseases in both humans and animals ${ }^{3,4}$ and their use is therefore banned in many countries. However, for many years, chrysotile was used in many applications and to construct various types of artifacts (asbestos cement, tubing, reinforcing agents, fire retardants, etc.). Recently, many studies and patents have dealt with the possible disposal and re-use of chrysotile-asbestos-containing materials (ACM), ${ }^{5-7}$ mainly through the crystal-chemical transformation induced by thermal treatment. ${ }^{8-13}$ It has been shown that both collapse temperature and chrysotile transformation products depend on the complex mineralogical composition of ACM. ${ }^{14}$ However, the main products of heat treatment of ACM are, in decreasing order of abundance, glass, olivine, enstatite, and diopside. ${ }^{7-15}$ These products can be recycled to produce stoneware tile mixtures, bricks, and concrete, ${ }^{8,16,17}$ incorporated into mortars ${ }^{10}$ or to provide

both refractoriness and reinforcement to other materials (e.g., road beds). Finally, thermal but not recycled materials must be moved in controlled landfill. On the other hand, several researchers are studying synthesized pure and doped chrysotile fibers for possible use as nanowires and for information on their pathological mechanisms by means of in vitro experiments. For this purpose, chrysotile fibers have been synthesized by hydrothermal treatment in various synthesis conditions and with various starting materials, ${ }^{18,19}$ including the main products of their thermal treatment, such as forsterite, ${ }^{20-25}$ diopside,${ }^{26}$ and enstatite, ${ }^{27}$ but not glass. The present work therefore studies the experimental conditions involved in the transformation of glass into chrysotile fibers and characterizes the resulting products. Also of interest is study of the risk that, over a long period of time, the glass produced by thermal treatment of ACM may be recrystallized to chrysotile fibers by contact with percolating solutions present in landfill in which ACM has been placed.

II. Experimental Procedure (1) Starting Materials and Glass Formation

To obtain glass, the following starting materials were used: $\mathrm{SiO}_{2}$ (granular quartz), $\mathrm{MgO}$ (periclase), $\mathrm{TiO}_{2}$ (gel), and $\mathrm{CaO}$ (calcium oxide). To increase the reactivity between nutrients, preheating was required in a vertical furnace equipped with a Super Kanthal heating element $\left(0^{\circ} \mathrm{C}-1700^{\circ} \mathrm{C}\right)$, with temperature controlled by PtRh-PtRh thermocouples (precision $\pm 4^{\circ} \mathrm{C}$ ). Granular quartz was converted into cristobalite by heating powdered $\mathrm{SiO}_{2}$ to $1400^{\circ} \mathrm{C} ; \mathrm{MgO}$ powders were heated to $900^{\circ} \mathrm{C}$, to eliminate hygroscopicity; $\mathrm{TiO}_{2}$ was applied as a gel, made with $\mathrm{TiCl}_{4}$ as starting material ${ }^{28}$; $\mathrm{CaO}$ was obtained by heating $\mathrm{CaCO}_{3}$ powder for $24 \mathrm{~h}$ to $900^{\circ} \mathrm{C}$ to remove $\mathrm{CO}_{2}$. All starting materials used in experiments had a purity exceeding $99 \%$.

The molar ratio of the starting materials for two sets of glass is given below:

1. $\mathrm{SiO}_{2}: \mathrm{MgO}: \mathrm{TiO}_{2}: \mathrm{CaO}=1: 1: 1: 1$

2. $\mathrm{SiO}_{2}: \mathrm{MgO}: \mathrm{TiO}_{2}: \mathrm{CaO}=0.77: 1.21: 0.06: 0.01$ 
The powdered mixtures were heated in a furnace at $1650^{\circ} \mathrm{C}$. The resulting melt was kept at this temperature for $48 \mathrm{~h}$ and then rapidly quenched down to room temperature by crucible

immersion in water. After some preliminary run tests to assess the most suitable condition to obtain glass, starting glass (1) was carried out at the same molar ratio oxides. Starting glass (2) was prepared with the same oxide wt\% quantities of $\mathrm{SiO}_{2}, \mathrm{MgO} \mathrm{TiO}_{2}$, and $\mathrm{CaO}$ detected in a natural asbestiform-like serpentine mineral called carlosturanite. ${ }^{29}$ This composition was used because the serpentine and serpentine-like mineral, carlosturanite is the richest in $\mathrm{CaO}$.

This oxide, as previously tested in starting glass (1), is in fact particularly suitable as melting agent and also present in the cement-asbestos such as calcite. ${ }^{8,9}$ The fact that glass has been obtained from starting materials (1) and (2) was confirmed by both SEM and XRPD (Figs. 1 and 2).

(2) Hydrothermal Alteration Reactions Glass fragments were cleaned by sonication in distilled water for 10 min, crushed in a mortar and sieved. The fraction of grains with size less than $0.177 \mathrm{~mm}$ was mixed with three types of reactants $\left(\mathrm{MgCl}_{2} \cdot 6 \mathrm{H}_{2} \mathrm{O}\right.$; $\mathrm{MgO}$; $\left.\mathrm{H}_{2} \mathrm{O}\right)$ for four sets of reactions, given

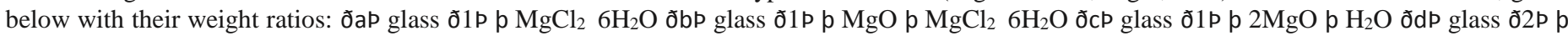
$\mathrm{H}_{2} \mathrm{O}$

Reactants $\mathrm{H}_{2} \mathrm{O}$ and $\mathrm{MgO}$ were added in stoichiometric ratios to yield chrysotile. These reactants were used because they had been previously tested in other works ${ }^{26}$ and they are particularly suitable as mineralizing agents for chrysotile fiber growth. About 100 mg of the reaction mixtures were sealed in platinum capsules and placed in externally heated pressure vessels. Several runs of hydrothermal synthesis were carried out in these vessels (Kanthal heating wire $0^{\circ} \mathrm{C}-1000^{\circ} \mathrm{C}$ ). Temperature was controlled by two chromel-alumel thermocouples (precision $\pm 2.5^{\circ} \mathrm{C}$, calibrated on the melting point of $\mathrm{NaCl}$, i.e., 800.5) placed near the hottest portion of the device. Pressure inside the vessels was supplied through a hydrostatic circuit and continuously monitored by a Nova Swiss (Cesson, France) transducer system (accuracy \pm 5 bar). Hydrothermal alteration reactions were performed in the following conditions: temperature $300^{\circ} \mathrm{C}-400^{\circ} \mathrm{C}$; pressure $100-200 \mathrm{MPa}$; time $48-480 \mathrm{~h}$. The capsules were then rapidly quenched in water at an estimated cooling rate of about $300^{\circ} \mathrm{C} / \mathrm{min}$. The experimental conditions are listed in Table I (glass 1) and Table II (glass 2).

\section{(3) Characterization Techniques}

The crystallinity of the starting material and the experimental run products were characterized by X-ray powder diffraction (XRPD), SEM, and TEM, with energy-dispersive X-ray spectroscopy (EDS). The XRPD patterns were obtained on a Philips PW 1730 (Philips, Eindhoven, The Netherlands) diffractometer, operating at $40 \mathrm{kV}$ and $20 \mathrm{~mA}$, with CuKa radiation. Scans were collected on powder samples in the range $3^{\circ}-60^{\circ} 2 \mathrm{~h}$ using a step interval of $0.02^{\circ} 2 \mathrm{~h}$, with a step counting time of $3 \mathrm{~s}$. Secondary electron SEM imaging was performed on a FEI Quanta 200 (FEI, Eindhoven, The Netherlands) equipped with a field emission gun. Morphological,

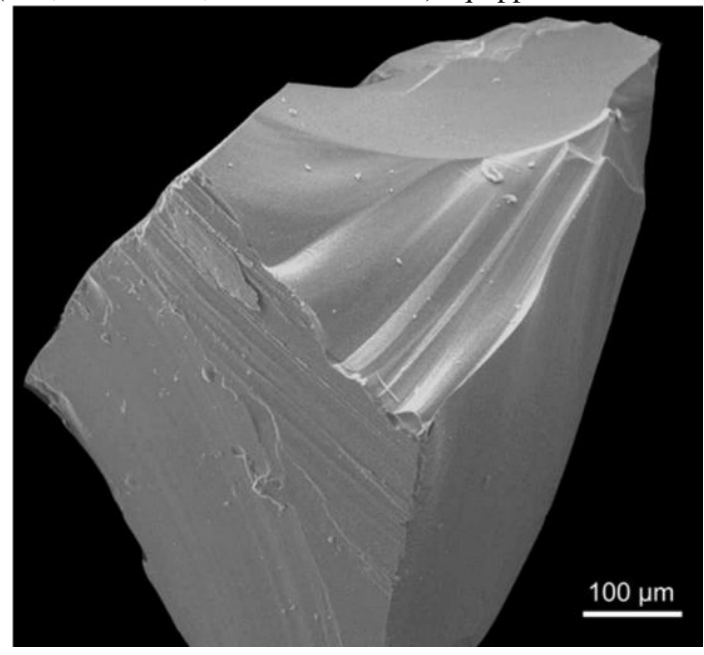

Fig. 1. Secondary electron SEM image of glass (1) fragment (starting materials 1). 


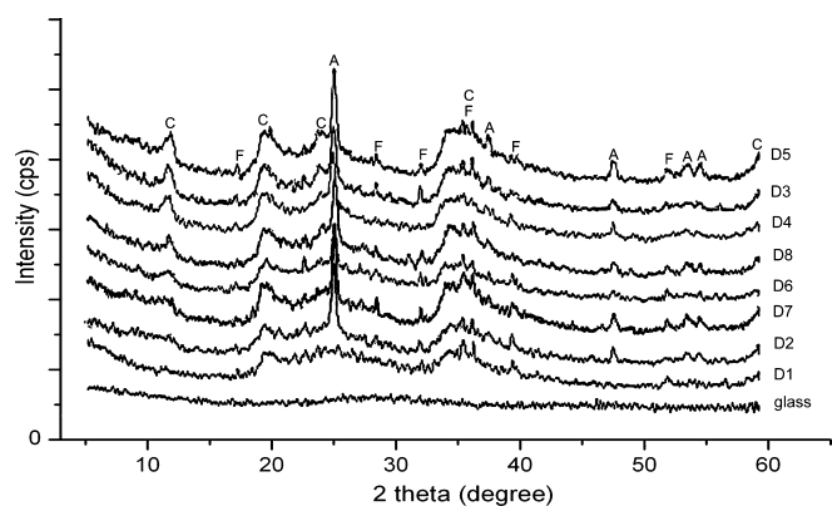

Fig. 2. XRPD pattern from starting material and products for glass (2) (Runs D1-D8, reactant $\mathrm{d}=$ glass $\left.(2)+\mathrm{H}_{2} \mathrm{O}\right)$. This last consists of $\mathrm{c}=$ chrysotile; $\mathrm{a}=$ anatase; $\mathrm{f}=$ forsterite. Peaks were assigned according to literature.

structural, and crystallinity features were examined on a TEM Philips CM12 (Philips, Eindhoven, The Netherlands), working at $120 \mathrm{kV}$ with a LaB6 filament with a double tilt holder. Analytical electron microanalyses (AEM) (not shown in this study) were performed on an EDS EDAX system with $\mathrm{Si} /(\mathrm{Li})$ with a detector attached. AEM data were processed using the SUPQ software PV9800 (Philips, Eindhoven, The Netherlands) system, with default $\mathrm{K}$ factors to obtain normalized quantitative data. For TEM/EDS investigations, a fragment of the whole run product was gently disaggregated in isopropyl alcohol in an agate and pestle mortar and sonicated, and two drops of the resulting suspension were deposited on a copper mesh grid coated with 200 Åcarbon film.

\section{Results and Discussion}

(1) Comparison of Products from Glass (1) and (2) The product from both sets of experiments was chrysotile. Other products, in decreasing order of abundance, were: geikielite, perovskite, calcite and brucite [glass (1)] (Table I), and anatase and forsterite [glass (2)] (Table II). In each case, as detected by TEM, starting materials in variable amounts were also present in all run products. In all runs, chrysotile fiber yields with water as mineralizing agent (reactions c, d) were always lower in abundance than those yielded by $\mathrm{MgCl}_{2} \cdot 6 \mathrm{H}_{2} \mathrm{O}(\mathrm{reactions}$ a, b). However, the yield from glass (2) (reaction d), although limited, showed that chrysotile fibers can be obtained without the aid of a mineralizing agent (reactions a, b) or other oxides such as $\mathrm{MgO}$ (reaction c). In glass (1) (reactions a, b, c) increasing the pressure of synthesis and time led to increasing fiber yields and sizes, whereas in glass (2) (reaction d) decreasing synthesis pressure increased chrysotile production. However, both diameter and length were greater from reactions c, d (only run D5) than reactions a, b. The formation of chrysotile fibers from glass (2) was anticipated by the formation of forsterite. This intermediate compound was easily obtained from glass (2) at $300^{\circ}$ $\mathrm{C}$ (runs D1, D2), further increases in temperature causing the formation of chrysotile fibers, following the transformations observed by TEM were well described already by Yada $\&$ Iishi. ${ }^{20}$ Instead, TEM investigations revealed that, in glass (1), chrysotile fibers do not grow through hydrothermal alteration of other intermediate products such as forsterite. 
Table I. Experimental Conditions and Product List of Synthesis for Each Run for Glass (1) in Order of Decreasing Abundance as Detected by XRPD, SEM, and TEM with EDS; Fibers Length and Diameter (Averages Values from Several Measures)

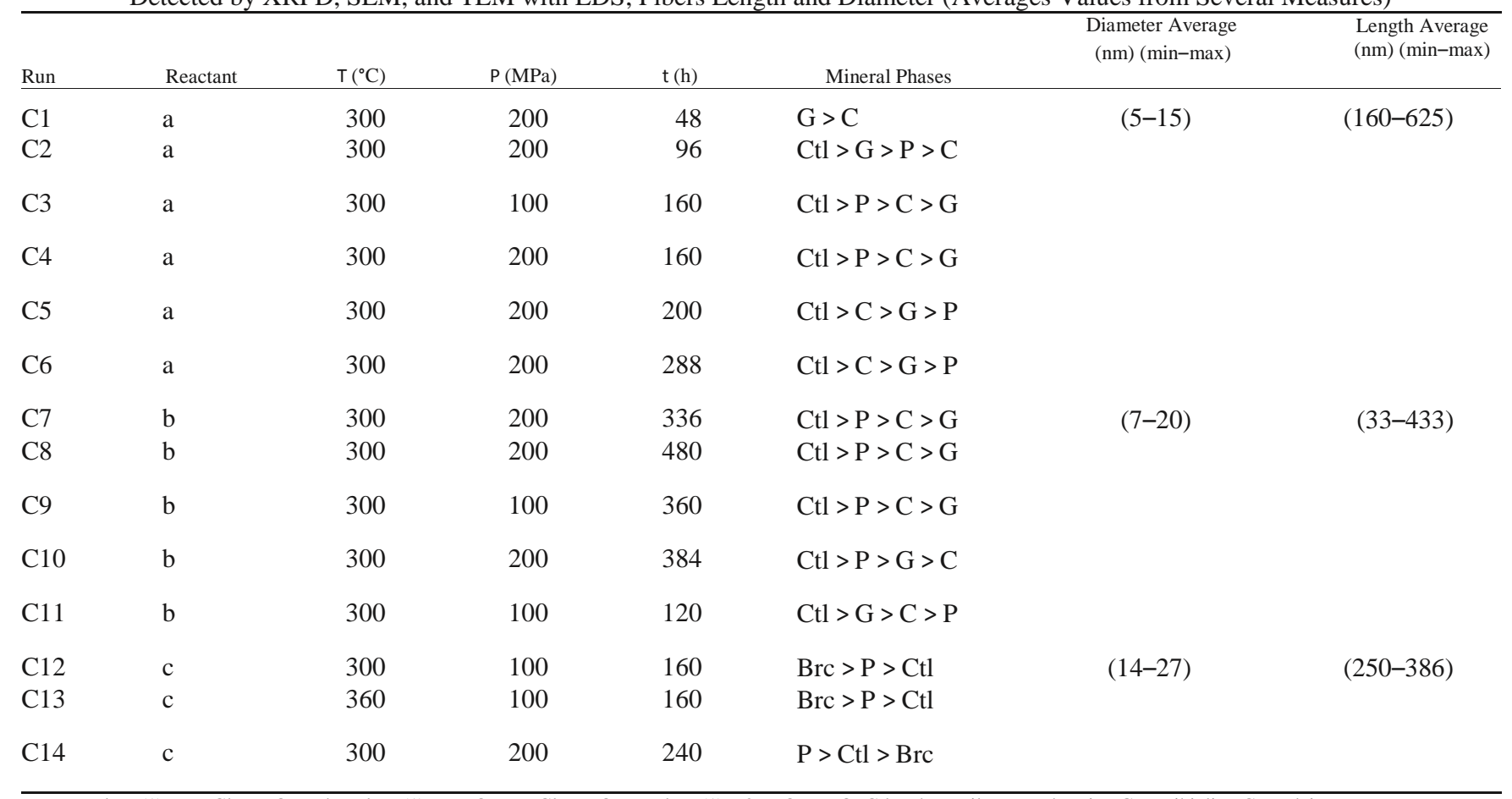

$\mathrm{a}=$ glass $(1)+\mathrm{MgCl}_{2} 6 \mathrm{H}_{2} \mathrm{O} ; \quad \mathrm{b}=$ glass $(1)+\mathrm{MgO}+\mathrm{MgCl}_{2} \cdot 6 \mathrm{H}_{2} \mathrm{O} ; \mathrm{c}=$ glass $(1)+2 \mathrm{MgO}+\mathrm{H}_{2} \mathrm{O} . \mathrm{Ctl}=$ chrysotile $;$ Brc = brucite $; \mathrm{G}=$ geikielite $; \mathrm{C}=$ calcite; $\mathrm{P}=$ perovskite.

Table II. Expermental Conditions and Products of Synthesis for Each Run for Glass (2) in Order of Decreasing Abundance as Detected by XRPD, SEM, and TEM-EDS

\begin{tabular}{|c|c|c|c|c|c|c|c|}
\hline Run & Reactant & $\mathrm{T}\left({ }^{\circ} \mathrm{C}\right)$ & $\mathrm{P}(\mathrm{MPa})$ & $\mathrm{t}(\mathrm{h})$ & Mineral Phases & $\begin{array}{l}\text { Diameter Average } \\
(\mathrm{nm})(\min -\max )\end{array}$ & $\begin{array}{l}\text { Length Average } \\
(\mathrm{nm})(\min -\max )\end{array}$ \\
\hline D1 & $\mathrm{d}$ & 300 & 100 & 160 & Fo & - & - \\
\hline D2 & $\mathrm{d}$ & 300 & 200 & 160 & $\mathrm{~A}>\mathrm{Fo}_{\mathrm{O}}$ & - & - \\
\hline D3 & $\mathrm{d}$ & 330 & 100 & 320 & $\mathrm{~A}>\mathrm{pC}>\mathrm{Fo}$ & - & - \\
\hline D4 & $\mathrm{d}$ & 330 & 100 & 160 & $\mathrm{~A}>\mathrm{Fo}>\mathrm{pC}$ & - & - \\
\hline D5 & $\mathrm{d}$ & 360 & 100 & 160 & $\mathrm{pC}>\mathrm{Ctl}>\mathrm{A}>\mathrm{Fo}$ & $(115-450)$ & $(9-85)$ \\
\hline D6 & $\mathrm{d}$ & 360 & 200 & 160 & $\mathrm{~A}>\mathrm{Fo}>\mathrm{pC}$ & - & - \\
\hline D7 & $\mathrm{d}$ & 400 & 100 & 160 & $\mathrm{Fo}>\mathrm{pC}>\mathrm{A}$ & - & - \\
\hline D8 & $\mathrm{d}$ & 400 & 200 & 160 & $\mathrm{Fo}>\mathrm{A}>\mathrm{pC}$ & - & - \\
\hline
\end{tabular}

= glass $(2)+\mathrm{H}_{2} \mathrm{O} . \mathrm{Ctl}=$ chrysotile; $\mathrm{A}=$ anatase; $\mathrm{Fo}=$ forsterite; $\mathrm{pC}=$ proto-chrysotile.

Results for Glass (1)

With the glass from glass (1), secondary products occurred rapidly, with the formation of calcite and geikielite (MgTiO 3 ) after 48 h of reaction. After $96 \mathrm{~h}$, chrysotile and perovskite $\left(\mathrm{CaTiO}_{3}\right)$ also appeared. An increase in the time of hydrothermal alteration of glass (1) (reactant a), at constant temperature and pressure $\left(300^{\circ} \mathrm{C}, 200 \mathrm{MPa}\right)$, produced larger fibers. With $\mathrm{MgCl}_{2} \cdot 6 \mathrm{H}_{2} \mathrm{O}$ as reactant $(\mathrm{Table} \mathrm{I}$; reactants a, b), chrysotile crystallized as the main phase. The most abundant production of chrysotile was obtained with reactant $\mathrm{b}$ after a long period (480 h, $200 \mathrm{MPa}, 300^{\circ} \mathrm{C}$, run C8; Table I). As regards the different set of reactions (Table I, runs C1-C14) glass composition does not seem to be crucial as mineralizing agent (i.e., $\mathrm{MgCl}_{2} \cdot 6 \mathrm{H}_{2} \mathrm{O}$ or water) in producing greater abundances of chrysotile fibers. When distilled $\mathrm{H}_{2} \mathrm{O}$ (reagent c) was used instead of $\mathrm{MgCl}_{2} \cdot 6 \mathrm{H}_{2} \mathrm{O}$ (reagents a, b) to alter glass (1), chrysotile yield decreased considerably, but an increase in both pressure and reaction time had the opposite effect (run C14). However, with $\mathrm{MgCl}_{2} \cdot 6 \mathrm{H}_{2} \mathrm{O}$ as reactant (reactant a, b), fiber diameter and length decreased with respect to chrysotile fibers obtained with distilled $\mathrm{H}_{2} \mathrm{O}$ as reagent (Table I; reagent c). TEM investigations showed that fibers obtained with reactant a (Fig. 3) had an average diameter smaller than those obtained with either reactants b or c (Figs. 4 and 5; Table I]. Only distilled water as reactant in glass (1) turned out to provide the best synthesis conditions for more abundant chrysotile, which was obtained at $300^{\circ} \mathrm{C}$ and $200 \mathrm{MPa}$, with a reaction time of $240 \mathrm{~h}$ (run C14). As regards morphology, in all sets of runs, fibers mostly showed the classical cylindrical morphology, but cone-in-cone shape was also detected. In all 


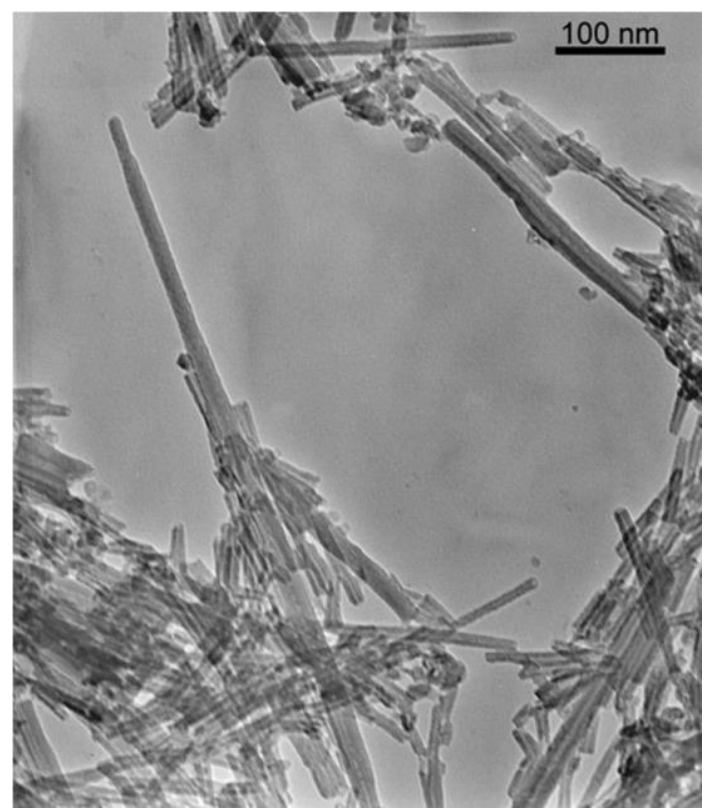

Fig. 3. Transmission electron micrograph of chrysotile fibers, as seen in the plane of fiber axis, from run $\mathrm{C} 4\left(300^{\circ} \mathrm{C}, 200 \mathrm{MPa}, 160 \mathrm{~h}\right), \mathrm{reactant} \mathrm{a}=\mathrm{glass}(1)+\mathrm{MgCl}_{2} 6 \mathrm{H}_{2} \mathrm{O}$.

runs with glass (1) (see Table I), fibers showed empty cores throughout their length, some cores being poorly shaped and partially filled.

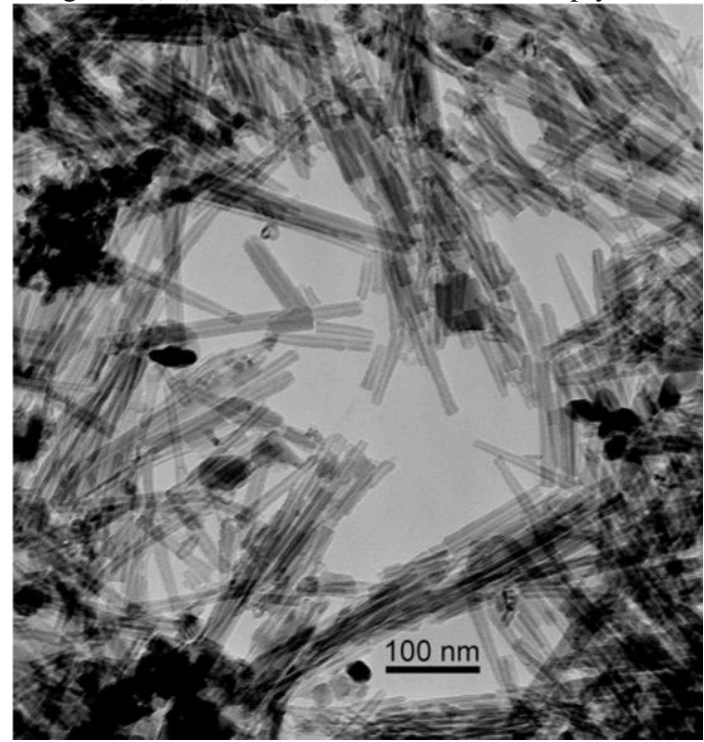

Fig. 4. Transmission electron micrograph of chrysotile fibers, as seen in the plane of fiber axis, from run $\mathrm{C} 8\left(300^{\circ} \mathrm{C}, 200 \mathrm{MPa}, 480 \mathrm{~h}\right)$, reactant $\mathrm{b}=\mathrm{glass}(1)+\mathrm{MgO}+$ $\mathrm{MgCl}_{2} \cdot 6 \mathrm{H}_{2} \mathrm{O}$.

(3) Results for Glass (2)

Subjecting glass (2) to various hydrothermal conditions, as shown by the XRPD patterns of Fig. 2, chrysotile was yielded at $400^{\circ} \mathrm{C}(100 \mathrm{MPa}$, $160 \mathrm{~h}$; run D7), although forsterite and anatase had already formed at $300^{\circ} \mathrm{C}\left(200 \mathrm{MPa}, 160 \mathrm{~h}\right.$; run D2). At $400^{\circ} \mathrm{C}$, a decrease in reaction pressure from 200 $\mathrm{MPa}$ (run D8) to $100 \mathrm{MPa}$ (run D7) slightly improved the amount of chrysotile produced. The XRPD reflection of the newly formed chrysotile became sharper with decreasing temperature from $400^{\circ} \mathrm{C}$ (Run D7) to $360^{\circ} \mathrm{C}$ (Run D5), corresponding to increases in chrysotile fiber size and abundance. However, when the temperature was decreased from $360^{\circ} \mathrm{C}$ (Run D5) to $330^{\circ} \mathrm{C}$ (Run D4) and then to $300^{\circ} \mathrm{C}$ (Run $\mathrm{D} 2$ ), there was no further increase in chrysotile yield. TEM micrograph (Fig. 6) shows the initial stages of serpentinization (run D7). After 160 h of hydrothermal reaction at $400^{\circ} \mathrm{C}$ and $100 \mathrm{MPa}$ (run D7), the main phase crystallizing as particles was forsterite, while chrysotile began to grow 


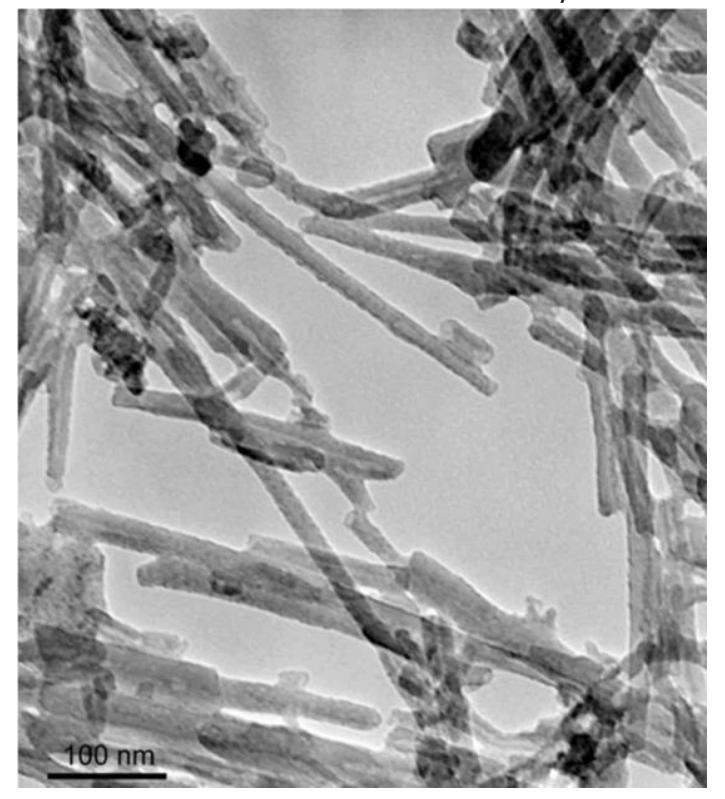

Fig. 5. Transmission electron micrograph of chrysotile fibers, as seen in the plane of fiber axis, from run $\mathrm{C} 12\left(300^{\circ} \mathrm{C}, 100 \mathrm{MPa}, 160 \mathrm{~h}\right)$, reactant $\mathrm{c}=\mathrm{glass}(1)+2 \mathrm{MgO}$ $+\mathrm{H}_{2} \mathrm{O}$.

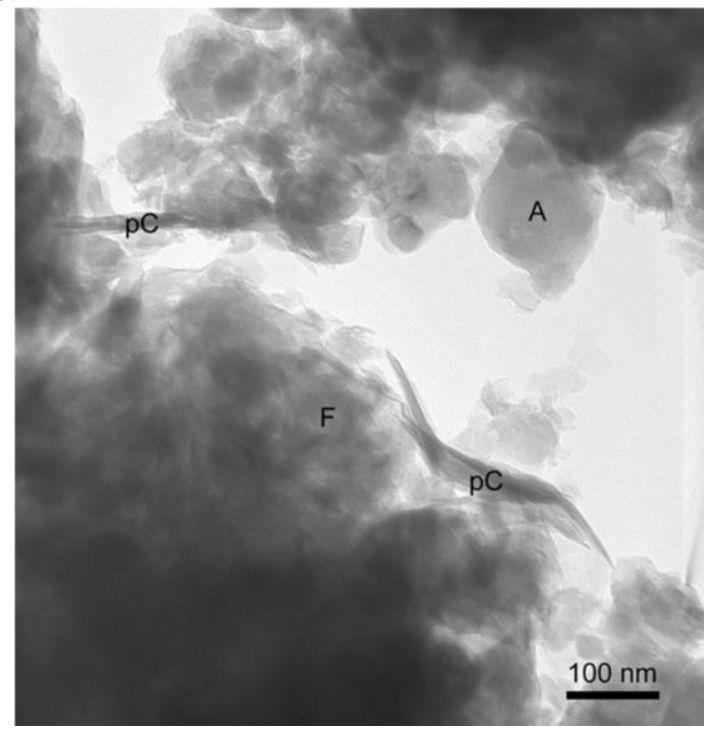

Fig. 6. Transmission electron micrograph of initial stage of chrysotile formation, from run $\mathrm{D} 7\left(400^{\circ} \mathrm{C}, 100 \mathrm{MPa}, 160 \mathrm{~h}\right)$, reactant $\mathrm{d}=\mathrm{glass}(2)+\mathrm{H}_{2} \mathrm{O} \cdot \mathrm{pC}=$ proto-chrysotile, $\mathrm{F}=$ forsterite, $\mathrm{A}=$ anatase.

from the surface of forsterite particles (Fig. 6). The surface seemed to peel off in many layers. These layers were partially wrapped and in some places appeared to be thicker, indicating greater curling of the T-O chrysotile layers. However, no chrysotile showing the classical cylindrical morphology with empty cores developed throughout the fiber length (run D7). In this stage, chrysotile grew with exclusively proto-chrysotile morphology ${ }^{30}$ and exhibited poor crystallinity, as confirmed by SAED investigations. Proto-chrysotile morphology is the precursor of the cylindrical morphology of chrysotile, as already extensively described by Yada \& Iishi ${ }^{20}$ and Muriel et al. ${ }^{30}$ However, the decrease of the temperature to $360^{\circ} \mathrm{C}$ (run D5) led to a decrease in the amount of proto-chrysotile, while the growth of the classical cylindrical chrysotile appeared. In comparison with other runs, in run D5 the chrysotile layers were thicker along the forsterite relict edges 


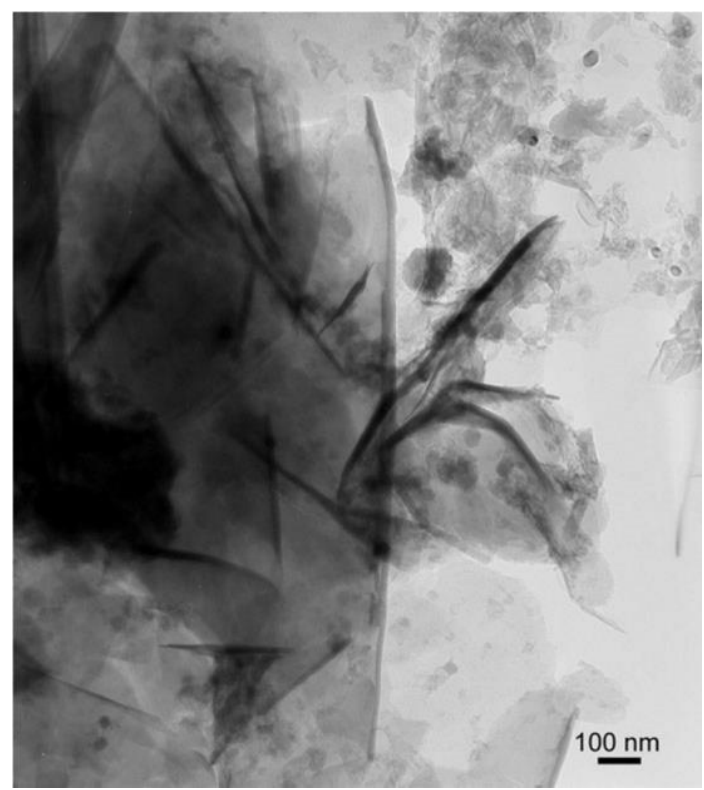

Fig. 7. Transmission electron micrograph of chrysotile layers via curling formed on the edge of forsterite relict, from run $\mathrm{D} 5\left(360^{\circ} \mathrm{C}, 100 \mathrm{MPa}, 160 \mathrm{~h}\right)$, reactant $\mathrm{d}=$ glass $(2)+\mathrm{H}_{2} \mathrm{O}$.

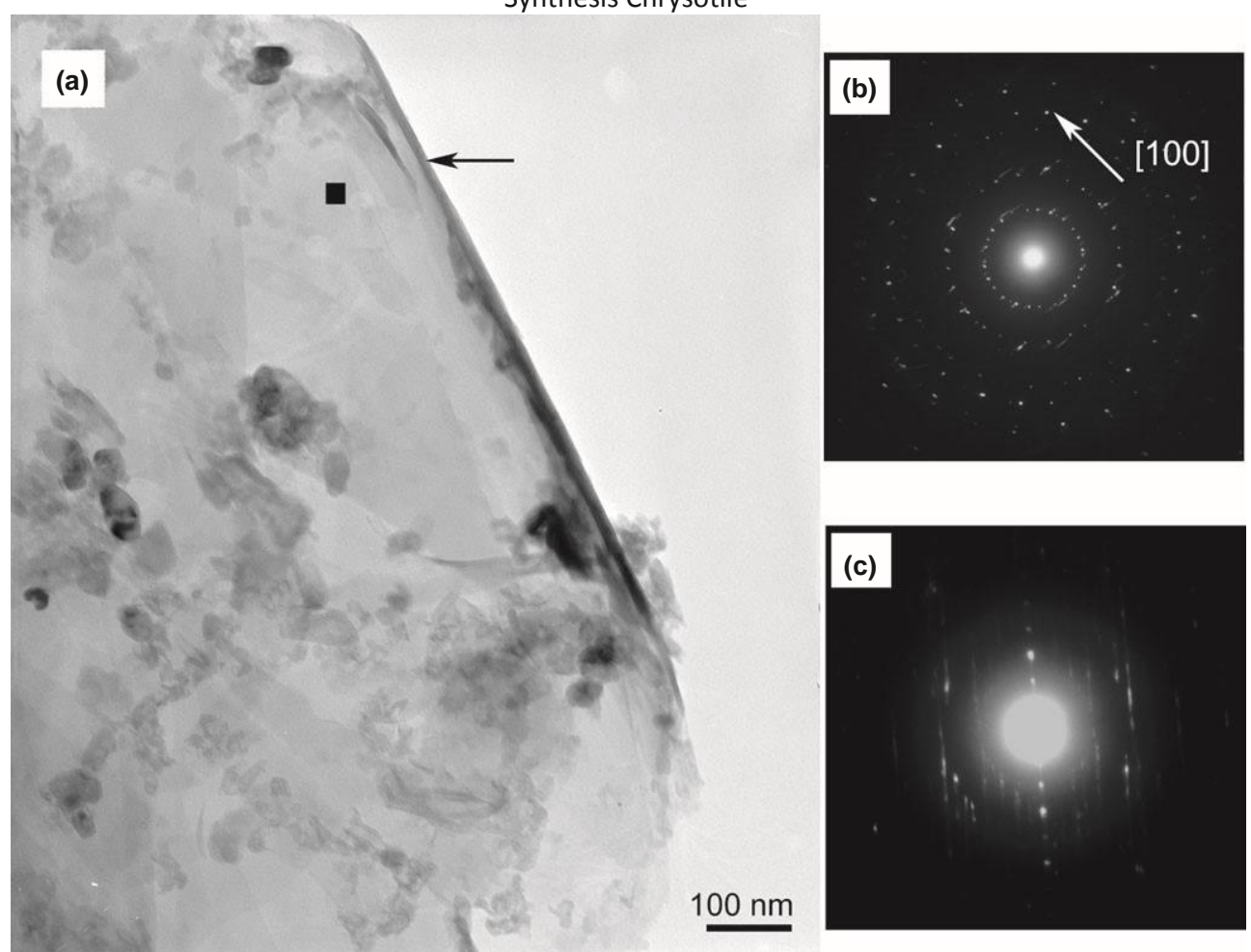

Fig. 8. Chrysotile via curling of the layers formed on the edge of forsterite relict, from run D5 $\left(360^{\circ} \mathrm{C}, 100 \mathrm{MPa}, 160 \mathrm{~h}\right)$, reactant $\mathrm{d}=$ glass $(2)+\mathrm{H}_{2} \mathrm{O}$. (a) Transmission electron micrograph, (b) electron diffraction pattern of chrysotile via curling indicated by arrow as seen on the fiber axis plane (c) electron diffraction pattern of forsterite relict, carried out on the point indicated by full black square in transmission electron

micrograph a). 


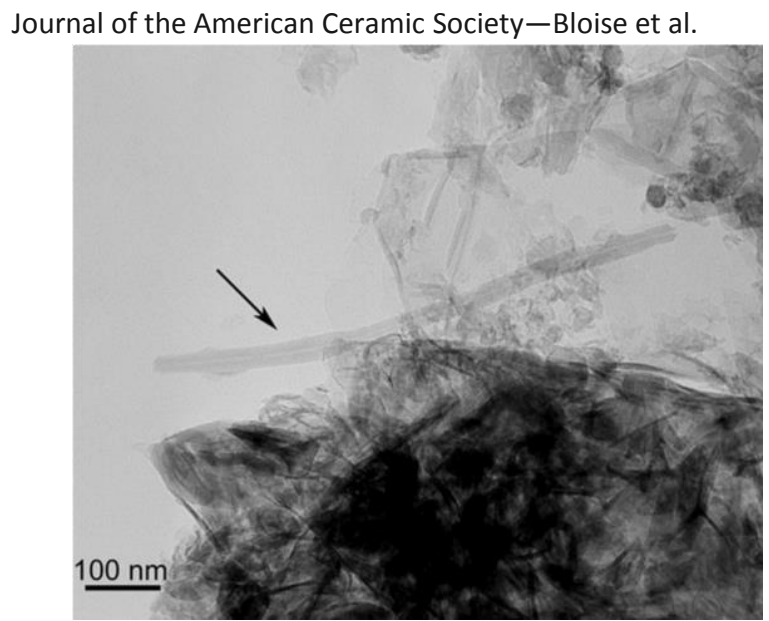

Fig. 9. Transmission electron micrograph of chrysotile fiber (indicated by arrow) and layers via curling, from run $\mathrm{D} 5\left(360^{\circ} \mathrm{C}, 100 \mathrm{MPa}, 160 \mathrm{~h}\right)$, reactant $\mathrm{d}=$ glass (2) $+\mathrm{H}_{2} \mathrm{O}$.

and the curling of the layers became more evident [Figs. 7 and 8(a)].

Figure 8(c) shows a SAED micrograph from the surface of the olivine relict and from the edge, where the membrane is being rolled up to form chrysotile fibers [Fig. 8(b)]. As this is a phase of transformation from forsterite to chrysotile, both SAED micrographs [Figs. 8(c) and (b)] show structural disorder. However, in Fig. 8(b), the typical splitting of the diffraction spots of the chrysotile fibers begins to appear, due to the cylindrical crystal lattice lying along layer lines. Lastly, as the XRPD pattern shows (Fig. 2), in run D5 crystallinity increases and the classical cylindrical morphology with a hollow central core running longitudinally along the fiber axis can be observed (Fig. 9), bent owing to interaction with the electron beam. However, TEM showed that only a few

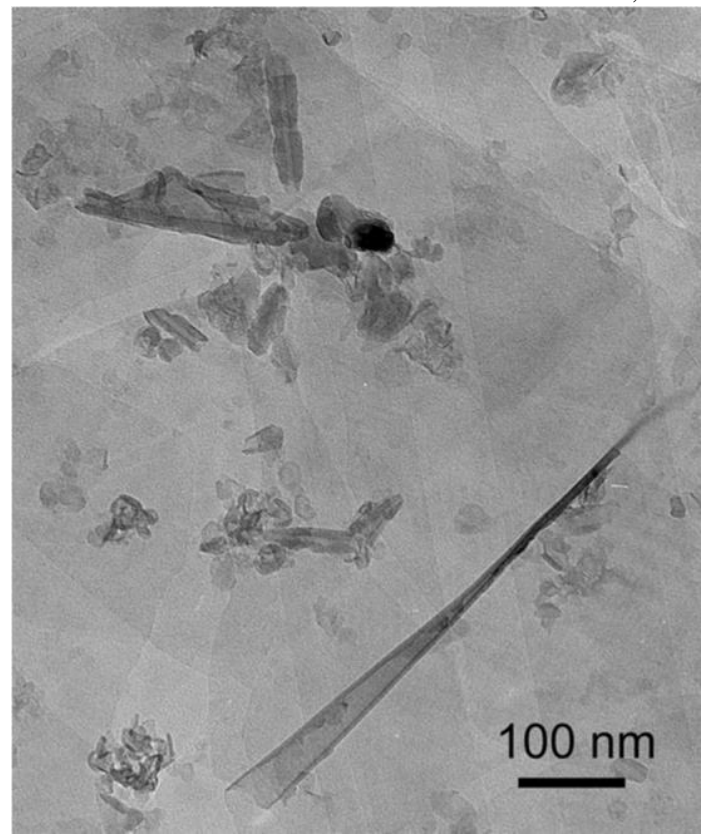

Fig. 10. Transmission electron micrograph of proto-chrysotile fibers from run D5 $\left(360^{\circ} \mathrm{C}, 100 \mathrm{MPa}, 160 \mathrm{~h}\right)$, reactant $\mathrm{d}=$ glass $(2)+\mathrm{H}_{2} \mathrm{O}$.

fibers have the typical cylindrical shape, proto-chrysotile being the most abundant morphology (Fig. 10). Some of the fibers do not have empty cores all the way along their axes, indicating the absence of core voids.

\section{IV. Conclusions}

Chrysotile fibers were synthesized from glass in hydrothermal conditions. On the whole, the best conditions for more abundant and greater lengthening of fibers were temperature at $300^{\circ} \mathrm{C}$, pressure at $200 \mathrm{MPa}$, long reaction times $(480 \mathrm{or} 240 \mathrm{~h})$ for glass $(1)$, and $360^{\circ} \mathrm{C}, 100 \mathrm{MPa}$, and $160 \mathrm{~h}$ for glass (2). Chrysotile fibers were easily obtained in large quantities from glass (1) but only in small amounts from glass (2), in which the lower quantity was probably due to the formation of intermediate products such as forsterite. Growth parameters (temperature, pressure, reaction time) required to obtain chrysotile fibers from glass (2) were very similar to those used to alter forsterite by other authors. Conversely, chrysotile formation was increased by treating glass (1) with a mineralizing agent such as $\mathrm{MgCl}_{2} \cdot 6 \mathrm{H}_{2} \mathrm{O}$ or $\mathrm{MgO}$, probably because the formation of forsterite was inhibited by the mineralizing agent. With $\mathrm{MgCl}_{2} \cdot 6 \mathrm{H}_{2} \mathrm{O}$ as mineralizing agent, more abundant production of chrysotile fibers was achieved, although they could also be obtained by altering glass (2) with distilled water only. It is concluded that the effect of mineralizing agent 
$\left(\mathrm{MgCl}_{2} \cdot 6 \mathrm{H}_{2} \mathrm{O}\right.$ or $\left.\mathrm{MgO}\right)$ prevailed over growth parameters as regards increased chrysotile fiber production, although prolonged reaction times led to larger fiber size.

In the light of these results also glass produced as a result of thermal treatment of ACM containing chrysotile, when placed in landfills, owing to possible long-term increases in temperature and pressure and contact with percolating solutions (i.e., natural water) can probably be hydrothermally altered and recrystallized to chrysotile. Instead,as regards recycling ACM into inert products (bricks, tiles, ceramics), the possibility of their recrystallization into chrysotile fibers in ambient conditions is probably remote. Further experimental runs are continuing, with the aim of recrystallizing chrysotile fibers from glass obtained by melting natural chrysotile fibers or ACM.

\section{References}

W. A. Deer, R. A. Howie, and J. Zussman, Rock-Forming Minerals Layered Silicates Excluding Micas and Clay Minerals, Vol. 3B. The Geological Society, London, (2009).

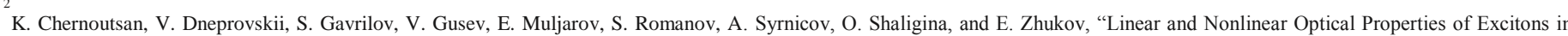
Semiconductor-Dielectric Quantum Wires," Physica E, 15, 111-7 (2002).

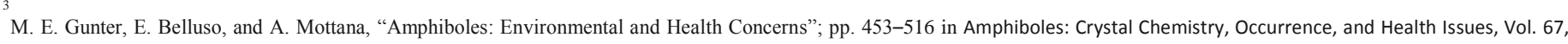
Reviews in Mineralogy \& Geochemistry, Edited by C. F. Hawthorne, R. Oberti, G. Della Ventura and A. Mottana

Mineralogical Soc. America Geochemical Soc., Chantilly, VA, 2007.

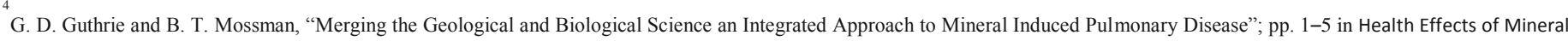
Dusts, Vol. 28, Reviews in Mineralogy \& Geochemistry. Edited by G. D. Guthrie and B. T. Mossman. Mineralogical Soc. America Geochemical Soc., Chelsea, MI, 1993.

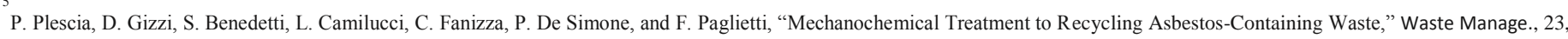
209-18 (2003).

S. E. Favero-Longo, D. Castelli, B. Fubini, and R. Piervittori, "Lichens on Asbestos-Cement Roofs: Bioweathering and Biocovering Effects," J. Hazard. Mater., 162, 1300-8 (2009).

7 K. Anastasiadou, D. Axiotis, and E. Gidarakos, "Hydrothermal Conversion of Chrysotile Asbestos Using Near Supercritical Conditions," J. Hazard. Mater., 179, 926-32 (2010).

${ }^{8}$ A. F. Gualtieri, C. Cavenati, I. Zanatto, M. Meloni, G. Elmi, and M. Lassinantti Gualtieri, "The Transformation Sequence of Cement-Asbestos Slates up to $1200^{\circ}$ C and Safe Recycling of the Reaction Product in Stoneware Tile Mixtures," J. Hazard. Mater., 152, 563-70 (2008).

F. Dellisanti, P. L. Rossi, and G. Valdre ' "Remediation of Asbestos Containing Materials by Joule Heating Vitrification Performed in a Pre-Pilot Apparatus," Int. J. Miner. Process., 91, 61-7 (2009).

10

Y. Yvon and P. Sharrock, "Characterization of Thermochemical Inactivation of Asbestos Containing Wastes and Recycling the Mineral Residues in Cement Products," Waste Biomass Valor., 2, 169-81 (2011).

D. N. Boccaccini, C. Leonelli, M. R. Rivasi, M. Romagnoli, P. Veronesi, G. C. Pellacani, and A. R. Boccaccini, "Recycling of Microwave Inertised Asbestos Containing Waste in Refractory Materials," J. Eur. Ceram. Soc., 27, 1855-8 (2007).

P. A. Candela, C. D. Crummett, D. J. Earnest, M. R. Frank, and A. G. Wylie, "Low-Pressure Decomposition of Chrysotile as a Function of Time and Temperature," Am. Mineral., 92 [10] 1704-13 (2007).

13

C. Leonelli, P. Veronesi, D. N. Boccaccini, M. R. Rivasi, L. Barbieri, F. Andreola, I. Lancellotti, D. Rabitti, and G. C. Pellacani, "Microwave Thermal Inertisation of Asbestos Containing Waste and its Recycling in Traditional Ceramics," J. Hazard. Mater., 135, 149-55 (2006).

${ }_{14}$ F. Dellisanti, V. Minguzzi, and N. Morandi, "Experimental Results from Thermal Treatment of Asbestos Cantaining Materials,” GeoActa, 1, 61-70 (2002).

15

C. Giacobbe, A. F. Gualtieri, S. Quartieri, C. Rinaudo, M. Allegrina, and G. B. Andreozzi, "Spectroscopic Study of the Product of Thermal Transformation on ChrysotileAsbestos Containing Materials," Eur. J. Mineral., 22 [4] 535-46 (2010).

A. F. Gualtieri, C. Giacobbe, L. Sardisco, M. Saraceno, M. L. Gualtieri, G. Lusvardi, C. Cavenati, and I. Zanatto, "Recycling of the Product of Thermal Inertization of Cement-

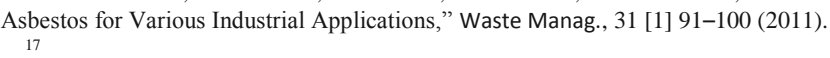

A. F. Gualtieri and M. Boccaletti, "Recycling of the Product of Thermal Inertization of Cement-Asbestos for the Production of Concrete," Construct. Build. Mater., 25, 3561-9 (2011)

18

N. Roveri, G. Falini, E. Foresti, G. Fracasso, I. G. Lesci, and P. Sabatino, “Geoinspired Synthetic Chrysotile Nanotubes,” J. Mater. Res., 21 [11] $2711-25$ (2006).

19

G. Falini, E. Foresti, G. Lesci, and N. Roveri, “Structural and Morphological Characterization of Synthetic Chrysotile Single Crystals,” Chem. Commun., 14, 1512-3 (2002).

K. Yada and K. Iishi, "Growth and Microstructure of Synthetic Chrysotile," Am. Mineral., 62, 958-65 (1977).

21

C. Normand, A. E. W. Jones, F. R. Martin, and H. Vali, "Hydrothermal Alteration of Olivine in a Flow-Through Autoclave: Nucleation and Growth of Serpentine Phases," Am. Mineral., 87, 1699-709 (2002).

A. Bloise, E. Barrese, and C. Apollaro, "Hydrothermal Alteration of TiDoped Forsterite to Chrysotile and Characterization of the Resulting Chrysotile Fibers," N. Jb. Miner. Mh., 185 [3] 297-304 (2009).

A. Bloise, E. Belluso, E. Fornero, C. Rinaudo, E. Barrese, and S. Capella, "Influence of Synthesis Condition on Growth of Ni-Doped Chrysotile," Microporous Mesoporous Mater., 132, 239-45 (2010).

${ }^{24}$ A. Bloise, E. Belluso, E. Barrese, D. Miriello, and C. Apollaro, "Synthesis of Fe-Doped Chrysotile and Characterization of the Resulting Chrysotile Fibers," Cryst. Res. Technol., 44 [6] 590-6 (2009).

A. Filippidis, "Experimental Study of the Serpentinization of Mg-Fe-Ni Olivine in the Presence of Sulfur," Can. Mineral., 20, 567-74 (1982).

26

E. Barrese, E. Belluso, and F. Abbona, “On the Transformation of Synthetic Diopside Into Chrysotile,” Eur. J. Mineral., 9, 83-7 (1997).

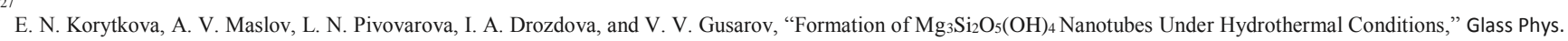
Chem., 30 [1] 51-5 (2004).

${ }^{28}$ Yu. V. Kolen'ko, A. A. Burukhin, B. R. Churagulov, and N. N. Oleinikov, "Phase Composition of Nanocrystalline Titania Synthesized Under Hydrothermal Conditions from Different Titanyl Compounds," Inorg. Mater., 40, 822-8 (2004).

29

${ }^{29}$ R. Compagnoni, G. Ferraris, and M. Mellini, “Carlosturanite, a New Asbestiform R-Forming Silicate from Val Varaita, Italy,” Am. Mineral., 70, 767-72 (1985).

A. Muriel, O. Grauby, A. Baronnet, and M. Muñ oz, "Occurence, Composition and Growth of Polyhedral Serpentine," Eur. J. Mineral., 20 [2] 159-71 (2008).h 